\title{
Dose-dependent cigarette smoking-related inflammatory responses in healthy adults
}

\author{
W.G. Kuschner*+\#, A. D'Alessandro*+*, H. Wong*\#, P.D. Blanc*+\#
}

Dose-dependent cigarette smoking-related inflammatory responses in healthy adults. W.G. Kuschner, A. D'Alessandro, H. Wong, P.D. Blanc. OERS Journals 1996.

ABSTRACT: The aim of this study was to determine the dose-response relationship between cigarette smoke exposure and pulmonary cell and cytokine concentrations in bronchoalveolar lavage (BAL).

BAL cells and BAL supernatant concentrations of tumour necrosis factor- $\alpha$ (TNF$\alpha$ ), interleukin (IL)-1 $\beta$, IL-6, IL-8, and monocyte chemoattractant protein (MCP)-1 from 14 healthy smokers and 16 healthy nonsmokers were quantified.

Statistically greater concentrations of neutrophils, macrophages, IL-1 $\beta$, IL-6, IL8 and MCP-1 were observed among smokers compared with nonsmokers $(p \leq 0.0007$ in all cases). Cigarette smoking, categorized ordinally as: less than one pack, one pack, or greater than one pack per day, was predictive of BAL macrophages $(p<0.0001)$, neutrophils $(p=0.015)$, IL-1 $\beta(p<0.001)$ and IL-8 $(p=0.02)$.

We conclude that concentrations of macrophages, neutrophils, IL-1 $\beta$ and IL-8 are elevated in the pulmonary microenvironment of smokers in a cigarette dosedependent manner. Based on the present findings, we would caution against simple analyses that treat current smokers as a homogeneous group and which do not account for smoking intensity.

Eur Respir J., 1996, 9, 1989-1994.

Increased concentrations of neutrophils and macrophages are recovered in the bronchoalveolar lavage (BAL) of smokers compared with nonsmokers [1-6]. However, we are not aware of any published reports delineating the dose-response relationship for cigarette smoking in packs $\cdot$ day $^{-1}$ as opposed to simple comparisons between smokers and nonsmokers defined dichotomously. Recent ex-vivo studies (BAL macrophages from smokers studied in vitro) indicate that cytokine regulation in the lung may be altered by cigarette smoke exposure [7-12]. As with BAL total cell concentrations, packs $\cdot$ day $^{-1}$ doseresponse relationships for cigarette-induced changes in pulmonary cytokine production have not been reported.

Delineating cell and cytokine dose-response relationships is important, not only because it is fundamental to testing causal relationships, but also because it may provide significant mechanistic insights into the proinflammatory effects of smoking. We wished to study the relationship between cigarette smoking intensity, quantified as volunteer-reported packs $\cdot$ day $^{-1}$, and BAL cell and cytokine concentrations. Analysis was focused on five cytokines, chosen a priori as pertinent to macrophage or neutrophil function: three proinflammatory mediators (tumour necrosis factor- $\alpha$ (TNF- $\alpha$ ), interleukin (IL)-1 $\beta$ and IL-6); and two chemoattractants (monocyte chemoattractant protein (MCP)-1 and the neutrophil chemoattractant, IL-8).
*Division of Occupational and Environmental Medicine, and +Division of Pulmonary and Critical Care Medicine, Dept of Medicine, and \#Cardiovascular Research Institute, University of California, San Francisco, California, USA. ‡Current affiliation: Ist. Di Medicina del Lavoro e Tossicologia Professionale e Ambientale, Universita'Degli Studi di Perugia, Perugia, Italy.

Correspondence: W.G. Kuschner, University of California, San Francisco, Division of Occupational and Environmental Medicine, 350 Parnassus Avenue, Suite 609, San Francisco, CA 94117, USA

Keywords: Bronchoalveolar lavage, cigarettes, cytokines, interleukins, monocyte chemoattractant protein-1, smoking

Received: November 171995

Accepted after revision June 151996

Supported in part by a National Research Service Award No. HL07185 and a University of California Tobacco Related Diseases Research Program New Investigator Award.

\section{Methods}

\section{Subjects}

The subjects studied were recruited through public advertisement. Smoking history and demographic information were obtained through an interviewer-administered structured questionnaire prior to study. Current smokers were asked to estimate the average number of cigarettes they smoked per day, and the number of years that they had smoked cigarettes. No information was obtained on patterns of inhalation, average butt length to which cigarettes were smoked, or brand of cigarette. Environmental tobacco smoke exposure was not assessed either for smokers or nonsmokers, and no attempt was made to account for exposure to other environmental pollutants. Selection age criteria was 18-45 yrs. Exclusion criteria were: chronic lung or heart disease with ongoing medical treatment; history of hepatitis; bleeding disorders; allergy to lidocaine; history of upper or lower respiratory tract infection within the preceding 4 weeks. Subjects were specifically asked whether they had ever been diagnosed with emphysema, any lung disease other than asthma, or heart disease. History of chronic cough or sputum production was not assessed.

Fourteen current smokers ( 8 males and 6 females) and 16 nonsmokers (8 males and 8 females) were studied. 
Table 1. - Demographic and smoking data for the subjects studied $(n=30)$

\begin{tabular}{|c|c|}
\hline \multicolumn{2}{|l|}{ Current smokers } \\
\hline Subjects $\mathrm{n}(\%)$ & $14(47)$ \\
\hline Age yrs $\#$ & $37 \pm 8 *$ \\
\hline \multirow[t]{2}{*}{ Current smoking packs $\cdot$ day $^{-1} \mathrm{n}^{+}$} & $1.1 \pm 0.6$ \\
\hline & $1.0(0.1-2)$ \\
\hline Duration of smoking yrs & $\begin{array}{l}18.0 \pm 5.9 \\
19(10-27)\end{array}$ \\
\hline Consumption pack-yrs $\ddagger$ & $\begin{array}{c}22.0 \pm 14.9 \\
22(1.8-54)\end{array}$ \\
\hline $\begin{array}{l}\mathrm{L}^{\#} \\
\% \text { pred }^{\#}\end{array}$ & $\begin{array}{l}3.7 \pm 0.7 \\
110 \pm 18\end{array}$ \\
\hline L $\mathrm{L}^{\#}$ pred $^{\#}$ & $\begin{array}{l}4.8 \pm 0.9 \\
114 \pm 15\end{array}$ \\
\hline $\begin{aligned} \text { FEV1/FVC } \% \# & \\
& \% \text { pred }^{\#}\end{aligned}$ & $\begin{array}{l}78 \pm 8 \\
97 \pm 10\end{array}$ \\
\hline \multicolumn{2}{|l|}{ Nonsmokers } \\
\hline \multirow{2}{*}{$\begin{array}{l}\text { Subjects } \mathrm{n}(\%) \\
\text { Age } \mathrm{yrs}^{+}\end{array}$} & $16(53)$ \\
\hline & $30 \pm 7 *$ \\
\hline Lifetime nonsmokers $\mathrm{n}(\%)$ & $11(37)$ \\
\hline Ex-smokers $\mathrm{n}(\%)$ & $5(17)$ \\
\hline \multirow{2}{*}{$\begin{array}{l}\text { Time since quitting for each subject yrs } \\
\text { Consumption pack-yrs }{ }^{+}\end{array}$} & $3,3,7,12,20$ \\
\hline & $4.5(3-18)$ \\
\hline \multirow{2}{*}{ FEV $1 \quad L^{\#}$} & $3.8 \pm 0.8$ \\
\hline & $108 \pm 14$ \\
\hline \multirow[t]{2}{*}{ FVC } & $4.8 \pm 0.9$ \\
\hline & $112 \pm 16$ \\
\hline \multirow{2}{*}{$\begin{aligned} \mathrm{FEV} 1 / \mathrm{FVC} & \%{ }^{\#} \\
& \% \text { pred }^{\#}\end{aligned}$} & $83 \pm 8$ \\
\hline & $101 \pm 10$ \\
\hline
\end{tabular}

\#: mean \pm SD; $\$$ : mean \pm SD, median, and range in parenthesis. FEV1: forced expiratory volume in second; $\%$ pred: percentage of predicted value; FEV: forced vital capacity. *: $p=0.02$, difference in age, smokers $v s$ nonsmokers.+. median and range in parenthesis

Demographic and smoking data for the subjects are summarized in table 1 . There was a wide range of cigarette smoking exposure among the subjects, in terms both of intensity and duration. Smoking intensity ranged from 2 cigarettes.day ${ }^{-1}$ to 2 packs of cigarettes $\cdot$ day $^{-1}$, and smoking duration ranged 10-27 yrs. The nonsmoking group included five individuals with prior smoking histories which were, in all but two cases, low level $(<5$ packyrs). All of the former smokers had ceased smoking cigarettes 3 yrs or more prior to study. All of the remaining 11 nonsmokers were lifetime nonsmokers.

The smokers (mean age $37 \pm 8$ yrs) were significantly older than the nonsmokers (mean age $30 \pm 7 \mathrm{yrs})(\mathrm{p}<0.05)$. The gender distribution, as noted, was similar. Of note, among adults, age up to $72 \mathrm{yrs}$ and gender have been shown to have no association with BAL findings [1]. Smokers were requested to refrain from smoking for at least $8 \mathrm{~h}$ prior to spirometry and BAL.

\section{Spirometry}

Spirometry was carried out on all subjects prior to bronchoscopy. As shown in table 1, there were no clinically relevant differences in pulmonary function between the smoking and nonsmoking groups.

\section{Bronchoscopy and BAL}

BAL was performed using a standardized technique. Bronchoscopy included routine atropine premedication and topical anaesthesia. A flexible fibreoptic bronchoscope (Pentax FB-19D; Pentax Precision Instrument Corporation, Orangeburg, NY, USA) was wedged in a segmental airway in the right middle lobe, and BAL was performed by instilling four $50 \mathrm{~mL}$ boluses of $37^{\circ} \mathrm{C}$ isotonic saline and applying gentle suction until no further collection was noted. The BAL was collected on ice.

The BAL was pooled. No gauze filtration was used. The percentage recovery of instilled lavage fluid was quantified. Differential cell counts were carried out by two or three readers, who were blinded to smoking intensity. A minimum of 300 cells in total was counted for each differential cell count. There were no complications resulting from bronchosccpy.

\section{Cytokine and protein determinations}

The remaining BAL fluid supernatant, after centrifugation, was stored at $-70^{\circ} \mathrm{C}$ for subsequent cytokine analysis. Concentrations of TNF- $\alpha$, MCP-1, IL- $1 \beta$, IL6 , and IL-8 in BAL supernatant were quantified by immunodetection with enzyme-linked immunosorbent assay (ELISA) (R\&D Systems, Minneapolis, MN, USA). The lower limits of detection of the kits (supplier's data) were as follows: TNF- $\alpha, 0.085 \mathrm{pg} \cdot \mathrm{mL}^{-1}$; MCP-1 $5.0 \mathrm{pg} \cdot \mathrm{mL}^{-1}$; IL-1 $\beta, 0.083 \mathrm{pg} \cdot \mathrm{mL}^{-1}$; IL-6 $0.080 \mathrm{pg} \cdot \mathrm{mL}^{-1}$; and IL-8 3.0 $\mathrm{pg} \cdot \mathrm{mL}^{-1}$. All samples were run in duplicate. Samples with cytokine concentrations below the limit of detection were assigned a cytokine concentration value that was one half of the lower limit of detection rather than a zero value. TNF- $\alpha$ was not detectable in BAL samples from seven nonsmokers and two smokers; MCP-1 in three smokers and one nonsmoker; and IL-1 in one nonsmoker. IL- 8 and IL- 6 concentrations were above the lower limit of detection in all samples. BAL supernatant total protein concentrations were determined using a commercially available colorimetric assay (Bio-Rad Laboratories, Hercules, CA, USA).

\section{Statistical analysis}

A standard statistical package was used for data analysis (Statistical Analysis System (SAS); SAS Institute Inc., Cary, NC, USA). Differences in demographic and lung function variables between smokers and nonsmokers were tested using the Student's t-test. In order to take into account the potential statistical impact of multiple comparisons in the analysis of BAL constituents, a hierarchical approach was adopted, as outlined by CuPPLEs et al. [13]. For the BAL cell constituents and separately for BAL supernatant constituents of a priori study interest, an overall Hotelling's statistic was first calculated, testing whether the variables as a group differed between smokers and nonsmokers. Since in both cases the overall differences were significant at the alpha 0.05 level, the individual parameters were then tested in a discriminant analysis. This takes into account the potential intercorrelations of the variables. Multiple comparisons were further accounted for by modifying the level of significance (alpha) to reject the null hypothesis based on the Bonferoni adjustment. 
In the next hierarchy of analysis, only those BAL cell or cytokine constituents that did indeed statistically differ between smokers and nonsmokers in the two previous independent analyses were examined seperately. Among the smoking stratum only $(n=14)$, least squares linear regression was used to estimate the effect of smoking exposure in packs. day $^{-1}$ either on BAL macrophages or neutrophils, or one of four cytokines: IL-1, IL-6, IL8 or MCP-1. In each case, a Bonferoni adjusted alpha, was used to assess the statistical significance of the estimated regression coefficients. In the final hierarchical level of analysis, BAL macrophage, neutrophil, IL-1, and IL-8 concentrations were further studied as dependent smoking-related variables using the entire study group $(n=30)$. For this analysis, smoking was defined ordinally. Three "dummy variables" were created, defining smoking status as low intensity (currently smoking $<1$ pack $\cdot$ day $^{-1}$; $\mathrm{n}=4)$; moderate $\left(1\right.$ pack $\cdot$ day $\left.^{-1} ; \mathrm{n}=5\right)$; or high intensity $(>1$ pack $\cdot$ day $\left.^{-1} ; n=5\right)$. The referent group comprised 16 nonsmokers. Multiple regression analysis was used, requiring in each case an overall model $F$ statistic $p<0.05$ to reject the null hypothesis before proceding to examine the individual regression coefficients. Because both BAL IL-8 and neutrophils were related to smoking intensity and were anticipated a priori to be related to each other, their correlation was also tested through least squares regression, treating neutrophil concentration as the dependent variable.

\section{Results}

\section{$B A L$ cellularity}

There was no meaningful difference in mean percentage recovery of instilled lavage between smokers $(66 \pm 8 \%)$ and nonsmokers $(67 \pm 12 \%),(\mathrm{p}=0.74)$. As shown in table 2 , smokers as compared to nonsmokers demonstrated significantly increased concentrations of BAL macrophages and neutrophils, but not other cell types. The overall proportion of neutrophils was $2.5 \pm 2.4 \%$ among smokers compared with $0.9 \pm 0.5 \%$ among nonsmokers $(\mathrm{p}=0.02)$.

Consistent with an exposure-response relationship, smoking intensity in packs $\cdot \mathrm{day}^{-1}$ among current smokers only $(n=14)$ was related to BAL macrophage concentration, although this association did not meet the Bonferoni adjusted alpha of 0.025 (fig. 1). Also as shown, smoking intensity analysed among smokers alone was not a

Table 2. - Mean bronchoalveolar lavage (BAL) cell concentrations in smokers and nonsmokers

\begin{tabular}{lcccc}
\hline Cell type & \multicolumn{2}{c}{$\begin{array}{c}\text { BAL concentration } \\
\times 10^{3} \text { cells } \mathrm{mL}^{-1} \\
\text { Smokers } \\
(\mathrm{n}=14)\end{array}$} & $\begin{array}{c}\text { Nonsmokers } \\
(\mathrm{n}=16)\end{array}$ & F statistic p-value \\
& $524 \pm 219$ & $220 \pm 98$ & 25.1 & 0.0001 \\
Macrophage & $52.9 \pm 13.3$ & $2.1 \pm 1.6$ & 10.6 & 0.003 \\
Neutrophil & $12.9 \pm 1.6$ & $14.8 \pm 17.7$ & 2.2 & 1.15 \\
Lymphocyte & $7.3 \pm 7.5$ & $1.1 \pm 1.3$ & 0.1 & 0.75 \\
Eosinophil & $0.9 \pm 1.7$ & $2.1 \pm 2.1$ & 1.0 & 0.33 \\
Epithelial & $1.5 \pm 1.4$ & & \\
\hline
\end{tabular}

Values are presented as mean \pm SD. Statistics quoted are by discriminant analysis. Overall model Hotelling's statistic $=1.7$; $\mathrm{p}=0.0001$. Critical Bonferoni alpha $(\mathrm{n}$ tests $=5)=0.01$.

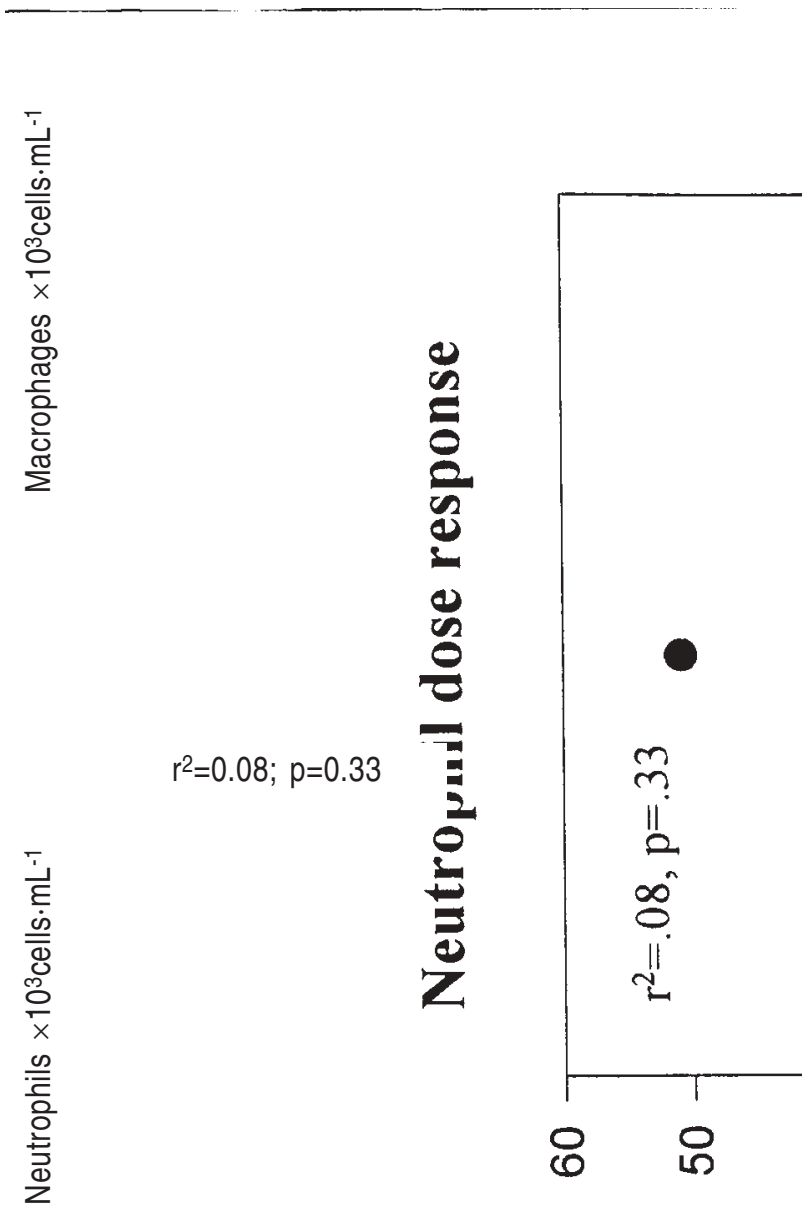

Fig. 1. - Dose-response relationships for cigarette smoking intensity (pack $\cdot$ day $^{-1}$ ) and a) bronchoalveolar lavage (BAL) macrophages and b) BAL neutrophils among cigarette smokers only $(n=14)$. The critical Bonferoni adjusted alpha, two-tailed, is 0.025 ( $\mathrm{n}$ tests $=2)$.

statistically significant predictor of neutrophil concentration. In order to further delineate the potential doseresponse relationships, macrophage and neutrophil responses were also studied by multivariate modelling $(n=30)$, which stratified subjects as either nonsmokers or low, moderate, or high intensity smokers. For macrophages, the overall smoking model effect was significant $(\mathrm{F}=$ 13.5; $\mathrm{p}<0.0001)$. Within the model, the estimated impact of low intensity smoking was an increase of $153 \times 10^{3}$ macrophages $\cdot \mathrm{mL}^{-1}$ BAL above baseline $(\mathrm{p}=0.08)$; an increase of $281 \times 10^{3}$ macrophages $\cdot \mathrm{mL}^{-1}$ for moderate smoking $(p=0.001)$; and an increase of $447 \times 10^{3}$ macrophages $\cdot \mathrm{mL}^{-1}$ for high intensity smoking $(\mathrm{p}=0.0001)$. For neutrophils, the overall smoking model effect was also significant $(\mathrm{p}=0.015)$. Within the model, the impact of low intensity smoking on neutrophils was not statistically significant (increase of $5 \times 10^{3}$ neutrophils $\cdot \mathrm{mL}^{-1} \mathrm{BAL}$, $\mathrm{p}=0.30$ ), whilst moderate smoking (increase of $12.9 \times 10^{3}$ neutrophils $\left.\cdot \mathrm{mL}^{-1}, \mathrm{p}=0.01\right)$ and high intensity smoking (increase of $13.1 \times 10^{3}$ neutrophils $\cdot \mathrm{mL}^{-1}, \mathrm{p}=0.009$ ) were 

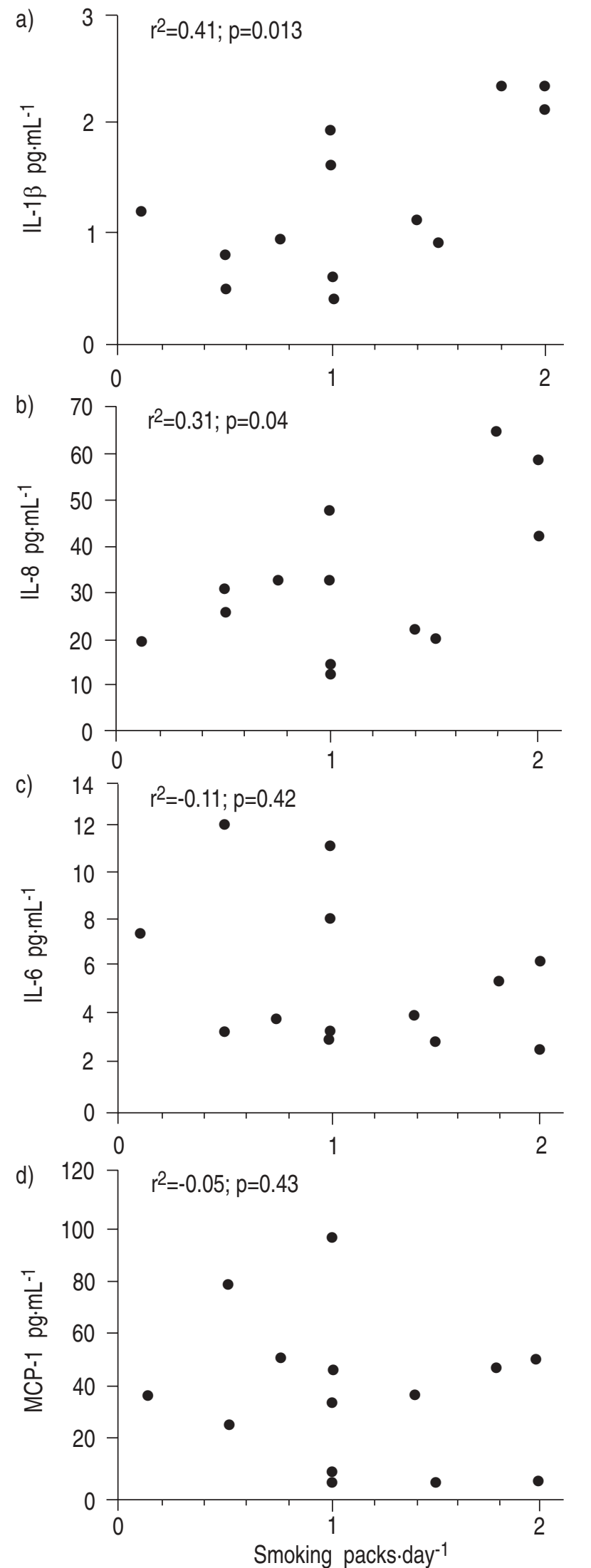

Fig. 2. - Dose-response relationships for cigarette smoking intensity (packs.day ${ }^{-1}$ ) and bronchoalveolar (BAL) supernatant cytokines among smokers only $(n=14)$. IL: interleukin; MCP-1: monocyte chemoattractant protein-1. The critical Bonferoni adjusted alpha, two-tailed, is 0.125 (n tests $=4)$.
Table 3. - Bronchoalveolar lavage (BAL) supernatant cytokine and total protein (TP) concentration differences between smokers and nonsmokers

\begin{tabular}{lccrl}
\hline BAL constituent & $\begin{array}{c}\text { Smokers } \\
(\mathrm{n}=14)\end{array}$ & $\begin{array}{c}\text { Nonsmokers } \\
(\mathrm{n}=16)\end{array}$ & $\begin{array}{c}\mathrm{F} \\
\text { statistic }\end{array}$ & p-value \\
\hline IL-1 $\beta \mathrm{pg} \cdot \mathrm{mL}^{-1}$ & $1.2 \pm 0.7$ & $0.5 \pm 0.4$ & 14.3 & 0.0007 \\
IL-6 $\mathrm{pg} \cdot \mathrm{mL}^{-1}$ & $5.3 \pm 3.2$ & $1.9 \pm 1.0$ & 17.3 & 0.0003 \\
IL- $\mathrm{pg} \cdot \mathrm{mL}^{-1}$ & $32.8 \pm 15.9$ & $18.2 \pm 11.5$ & 8.4 & 0.007 \\
TNF- $\alpha \mathrm{pg} \cdot \mathrm{mL}^{-1}$ & $2.5 \pm 7.9$ & $0.2 \pm 0.2$ & 1.4 & 0.25 \\
MCP-1 $\mathrm{pg} \cdot \mathrm{mL}^{-1}$ & $36.7 \pm 28.3$ & $13.0 \pm 7.7$ & 10.4 & 0.003 \\
TP $\mu \mathrm{g} \cdot \mathrm{mL}^{-1}$ & $75.8 \pm 27.7$ & $87.2 \pm 56.5$ & 0.4 & 0.50 \\
\hline
\end{tabular}

Values are presented as mean \pm SD. IL-1 $1 \beta$ : Interleukin- $1 \beta$ (nondetectable in one nonsmoker); IL-6: interleukin-6 (detected in all subjects); IL-8: interleukin-8 (detected in all subjects); TNF$\alpha$ : tumour necrosis factor- $\alpha$ (detectable in seven nonsmokers and two smokers); MCP-1: macrophage chemoattractant protein-1 (nondetectable in one nonsmoker and three smokers). Statistics quoted are by discriminant analysis. Overall model Hotelling's statistic $=1.34 ; \mathrm{p}<0.002$. Critical Bonferoni alpha value $(\mathrm{n}$ tests $=6)=0.008$

both statistically significant but quite similar to each other (i.e. no step-up in dose effect).

\section{BAL supernatant cytokines and protein}

Among smokers, there were statistically greater concentrations of the BAL supernatant constituents tested (Hotelling's statistic $\mathrm{p}<0.002$ ) (table 3 ). However, tested individually and taking into account a Bonferoni alpha of 0.008 , there were statistically significant differences only for IL-1 $\beta$, IL- 6 , IL- 8 and MCP-1. The potential smoking effect was further studied by limiting the analysis to the 14 current smokers and to only those four cytokines elevated in the smoking group. The doseresponse relationships are illustrated in figure 2 . There was a positive correlation between smoking intensity, expressed in packs.day ${ }^{-1}$, and the concentration of IL-1 $\beta$ which did not achieve statistical significance given the four models and a Bonferoni adjustment $\left(r^{2}=0.41 ; p=\right.$ $0.013)$. Similarly, there was also a positive association with IL-8 $\left(\mathrm{r}^{2}=0.31 ; \mathrm{p}=0.04\right)$ that did not meet the Bonferoni cut-off (alpha $=0.0125$ ). There was no correlation between smoking intensity and either IL-6 or MCP-1. The dose response for IL-1 $\beta$ and IL- 8 was further delineated by multivariate modelling, which included smokers and nonsmokers $(n=30)$ and which stratified smokers as either low, moderate, or high intensity smokers, as for macrophages and neutrophils. For IL- $1 \beta$, the overall smoking effect model was significant $(\mathrm{F}=-8.5 ; \mathrm{p}=0.0004)$. Low intensity smoking did not have a statistically significant impact on IL-1 $\beta$ concentration in BAL fluid $(0.4$ $\left.\mathrm{pg} \cdot \mathrm{mL}^{-1} ; \mathrm{p}=0.16\right)$ in this model. Moderate smoking intensity had an estimated impact of an additional 0.6 $\mathrm{pg} \cdot \mathrm{mL}^{-1}$ IL-1 $\beta$ above baseline nonsmoking values for BAL fluid $(\mathrm{p}=0.04)$. High intensity exposure yielded an estimated impact of an additional $1.3 \mathrm{pg} \cdot \mathrm{mL}^{-1} \mathrm{IL}-1 \mathrm{p}=$ $0.0001)$. For IL-8, the smoking effect model was also significant $(\mathrm{F}=4.1 ; \mathrm{p}=0.02)$. The estimated impact on IL$8 \mathrm{BAL}$ fluid concentrations of low intensity $\left(9 \mathrm{pg} \cdot \mathrm{mL}^{-1}\right.$; $\mathrm{p}=0.2)$ and moderate intensity $\left(10 \mathrm{pg} \cdot \mathrm{mL}^{-1} ; \mathrm{p}=0.2\right)$ smoking were not significant. In contrast, high intensity 
smoking yielded an estimated increase in IL-8 of 23 $\mathrm{pg} \cdot \mathrm{mL}^{-1}$ above nonsmokers $(\mathrm{p}=0.002)$. When analysed as a group $(n=30)$, the overall correlation between neutrophils and IL-8 was significant $(r=0.59 ; \mathrm{p}=0.0005)$, consistent with the established neutrophil chemoattractant effects of IL-8.

\section{Discussion}

The result of the present study suggest that increased cigarette smoking intensity is associated with dose-dependent increases in the concentrations of BAL macrophages and neutrophils. The findings are entirely consistent with published data on smoking defined dichotomously [1-6]. Furthermore, they suggest that increased smoking manifests an exposure dose-response for BAL supernatant concentrations of two proinflammatory cytokines, IL-1 and IL-8. These data suggest that, in studying inflammatory responses and mechanisms in individuals exposed to cigarette smoke, exposure intensity is an important variable. It may be inappropriate to make simple "dichotomous" divisions between smokers and nonsmokers. The significance of the correlations reported here should not, however, be overstated; correlation does not equate with causality.

A limitation of the present study is that the smoking dose determinations may be imprecise. Specifically, other relevant factors of smoking exposure were not consisered, including smoking technique, cigarette brand, tar content, or urine cotinine. However, decreased precision of data on smoking dose would probably reduce study power to detect significant associations between smoking dose and BAL cell and cytokine responses. Decreased precision in cytokine determination in dilute BAL supernatant would affect the study power in a similar manner. Another study limitation is our inability to comment on regional differences in inflammation (e.g. airways as opposed to alveoli). Finally, the small study size and the extremely conservative alpha criteria provide power to detect only relatively potent exposure effects. There may be more subtle smoking effects, therefore, which did not achieve statistical significance in this analysis.

The findings of increased concentrations of proinflammatory cytokines in the pulmonary microenvironment of smokers are in contrast with observations from some in vitro studies that indicate that cigarette smoke exposure may lead to decreased release of IL-6 [7, 10-12], and decreased production and release of IL-1 $[8,9,11]$ from the macrophages of smokers compared with nonsmokers studied ex-vivo. A number of factors may account for the differences between the present observations and these findings. Cells other than alveolar macrophages, including airway epithelial cells, probably play important roles in the regulation of cigarette smoking-induced pulmonary inflammatory responses. Airway epithelial cells have been shown to synthesize a number of important multifunctional cytokines, including each of those studied: IL-1 $\beta$ [14], IL-6 [15, 16], TNF- $\alpha$ [14], IL-8 [17], and MCP-1 [18]. Furthermore, cell-to-cell communication between alveolar macrophages and pulmonary epithelial cells has been shown to be important in epithelial cell gene expression for proinflammatory cytokines, underscoring the importance of interaction among different inflammatory cell types in pulmonary inflammatory responses [19, 20].
As a consequence, in vitro studies on isolated alveolar macrophages are limited, in that they cannot easily characterize cell-to-cell interactions and cytokine networking in inflammatory responses.

We view our findings as both hypothesis testing and hypothesis generating. Further studies to explore the relationship between cigarette smoking dose and inflammatory responses should include additional measurements to quantify smoking exposure dose with greater precision. Other important responses to consider, in addition to bronchoalveolar lavage cell and cytokine concentrations, could include measurements of inflammatory cell activation and evidence of clinically relevant smokingassociated physiological or structural effects.

Acknowledgement: The authors thank H. Boushey for his assistance with bronchoscopy.

\section{References}

1. The BAL Co-operative Group Steering Committee. Bronchoalveolar lavage constituents in healthy individuals, idiopathic pulmonary fibrosis, and selected comparison groups. Am Rev Respir Dis 1990; 141: S169-S202.

2. Reynolds HY, Merrill WW. Airway changes in young smokers that may antedate chronic obstructive lung disease. Med Clin North Am 1981; 65: 667-689.

3. Low RB, Davis GS, Giancola MS. Biochemical analyses of bronchoalveolar lavage fluids of healthy human volunteer smokers and nonsmokers. Am Rev Respir Dis 1978; 118: 863-875.

4. Burke WMJ, Roberts CM, Bryant DH, et al. Smokinginduced changes in epithelial lining fluid volume, cell density, and protein. Eur Respir J 1992; 5: 780-784.

5. Merchant RK, Schwzrtz DA, Helmers RA, Dayton CS, Hunninghake GW. Bronchoalveolar lavage cellularity: the distribution in normal volunteers. Am Rev Respir Dis 1992; 146: 448-453.

6. Barbers RG, Gong H, Tashkin DP, Oishi J, Wallace JM. Differential examination of bronchoalveolar lavage cells in tobacco cigarette and marijuana smokers. Am Rev Respir Dis 1987; 135: 1271-1275.

7. McCrea KA, Ensor JE, Nall K, Bleecker ER, Hasday JD. Altered cytokine regulation in the lungs of cigarette smokers. Am J Respir Crit Care Med 1994; 150: 696-703.

8. Yamaguchi E, Itoh A, Furuya K, Miyamoto H, Abe S, Kawakami Y. Release of tumor necrosis factor- $\alpha$ from human alveolar macrophages is decreased in smokers. Chest 1993; 103: 479-483.

9. Brown GP, Iwamoto GK, Monick MM, Huddinghake GW. Cigarette smoking decreases interleukin-1 release by human alveolar macrophages. Am J Physiol 1989; 256: C260-264.

10. Soliman DM, Twigg HL. Cigarette smoking decreases bioactive interleukin-6 secretion by alveolar macrophages. Am J Physiol 1992; 263: L471-L478.

11. Sauty A, Manuel J, Philippeaux M, Leuenberger P. Cytostatic activity of alveolar macrophages from smokers and nonsmokers: role of interleukin- $1 \beta$, interleukin6, and tumor necrosis factor- $\alpha$. Am J Respir Cell Mol Biol 1994; 11: 631-637.

12. Dubar V, Gosset P, Aerts C, Voisin C, Wallaert B, Tonnel $\mathrm{AB}$. In vitro acute effects of tobacco smoke on tumor necrosis factor- $\alpha$ and interleukin- 6 production by alveolar macrophages. Exp Lung Res 1993; 19: 345-359. 
13. Cupples LA, Heeren T, Schatzkin A, Colton T. Multiple testing of hypotheses in comparing two groups. Ann Int Med 1984; 100: 122-129.

14. Devalia JL, Campbell AM, Sapsford RJ, et al. Effect of nitrogen dioxide on synthesis of inflammatory cytokines expressed by human bronchial epithelial cells in vitro. Am J Respir Cell Moll Biol 1993; 9: 271-278.

15. Levine SJ, Larivee P, Logun C, Angus CW, Shelhamer JH. Corticosteroids differentially regulate secretion of IL6, IL-8 and G-CSF by a human bronchial epithelial cell line. Am J Physiol: Lung Cell Mol Physiol 1993; 265: L360-L368.

16. Bedard M, McClure CD, Schiller NL, Francoeur C, Cantin A, Denis M. Release of interleukin-8, interleukin-6, and colony-stimulating factors by upper airway epithelial cells: implications for cystic fibrosis. Am J Respir Cell Mol Biol 1993; 9: 455-462.
17. Nakamura H, Yoshimura K, Jaffe HA, Crystal RG. Interleukin-8 gene expression in human bronchial epithelial cells. J Biol Chem 1991; 266: 19611-19617.

18. Becker S, Quay J, Koren HS, Haskill JS. Constitutive and stimulated MCP-1, GRO alpha, beta and gamma expression in human airway epithelium and bronchoalveolar macrophages. Am J Physiol: Lung Cell Mol Physiol 1994; 266: L278-L286.

19. Standiford TJ, Kunkel SL, Basha MA, et al. Interleukin8 gene expression by pulmonary epithelial cell line: a model for cytokine networks in the lung. J Clin Invest 1990; 86: 1945-1953.

20. Standiford TJ, Kunkel SL, Phan SH, Rollins BJ, Streiter RM. Alveolar macrophage-derived cytokines induce monocyte chemoattractant protein-1 expression from human pulmonary type II-like epithelial cells. J Biol Chem 1991; 266: 9912-9918. 